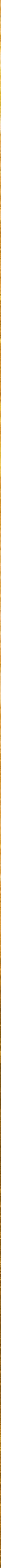




\section{Redes organizacionais: um estudo das estratégias de competitividade em cooperativas da agricultura familiar do oeste de santa catarina}

Organizational networks: a study of strategies on competitiveness of cooperative family farm of st santa catarina DOI: $10.15213 /$ REDES.N12.P242

DAVID RODRIGO PETRY, CITANIA APARECIDA PILATTI, CRISTIANE ZUCCHI, SILVIO SANTOS JUNIOR

\section{RESUMO}

Este estudo teve como objetivo identificar estratégias a serem adotadas pelas cooperativas agroalimentares associadas à CECAF visando fortalecer sua participação no mercado. Apresenta constructos teóricos abrangendo conceitos de estratégia competitiva, redes e o modelo agrícola catarinense de alternativas de produção na agricultura familiar. Contou com coleta de dados por meio de questionários aplicados às cooperativas associadas à CECAF e outro questionário aplicado à população local visando identificar sua aceitação com relação aos produtos comercializados. Utilizou-se também para coleta de dados uma entrevista com o presidente da CECAF com intuito de contribuir para a análise dos dados. Os resultados da pesquisa demonstram que há preocupação dos afiliados com relação a maiores investimentos em marketing dos produtos, além da necessidade de maiores investimentos e parcerias visando melhorar a qualidade dos produtos ofertados. Outro fator que ficou evidenciado é que não há investimentos em diferenciação, como por exemplo, produtos orgânicos e inspecionados, fatores que poderiam ser utilizados para contribuir para a renda dos cooperados.

PALAVRAS-CHAVE: REDES; AGRICULTURA FAMILIAR; COMPETITIVIDADE; COOPERATIVAS. 


\section{ABSTRACT}

This study aimed to identify strategies to be adopted by agrifood cooperatives associated with CECAF order to strengthen its market share. Presents theoretical constructs covering competitive strategy concepts, networks and Santa Catarina agricultural model of production alternatives in family farming. Included data collection through questionnaires given to cooperatives associated with CECAF and another questionnaire applied to the local population to identify its acceptance with respect to products sold. We also used for data collection an interview with the president of CECAF aiming to contribute to the analysis of the data. The survey results show that there is concern from members with respect to increased investments in marketing of products, and the need for further investment and partnerships aimed at improving the quality of products offered. Another factor that was evident is that there is investment in differentiation, such as organic and inspected products, factors that could be used to contribute to the income of members.

KEYWORDS: NETWORKS; FAMILY AGRICULTURE; COMPETITIVENESS; COOPERATIVES.

\section{INTRODUÇÃo}

Grandes mudanças vêm ocorrendo no espaço rural nas últimas décadas, dentre as quais, a estagnação da economia voltada ao setor agroindustrial e a forte ocorrência do êxodo rural podem ser considerados os principais responsáveis por estas transformações, visto que esses fatores ocorrem desde a Revolução Industrial. (OLIVEIRA, 2013) Dados do IBGE, denotam significativo aumento do êxodo rural em Santa Catarina, passando de 57,1\% que viviam em áreas rurais na década de 70, para menos de $20 \%$ no ano de 2010.

Ferrari (2003) em seus estudos destaca que são necessárias novas abordagens para acompanhar as novas funções e a organização social emergente nas configurações de estudos aplicados ao meio rural, dentre elas, a nova visão de desenvolvimento rural e territorial, qualidade dos produtos e economia do meio ambiente, ou seja, perspectivas voltadas às mudanças institucionais, socioeconômicas e de trabalho. $\mathrm{O}$ autor afirma ainda que no Brasil, e particularmente em Santa Catarina, a chamada agricultura familiar é o maior segmento em número de estabelecimentos agrícolas e de pessoas ocupadas no meio rural e tem significativa importância econômica em diversas cadeias produtivas. 
Concomitantemente, a agricultura familiar também apresenta um papel muito importante na redução do êxodo rural e no potencial de criar condições e oportunidades de trabalho por meio de diversificados sistemas de produção e utilização dos recursos naturais. (LOURENZANI, 2006).

$\mathrm{Na}$ região Oeste de Santa Catarina, onde a economia é caracterizada por agricultores familiares descendentes de imigrantes europeus, vindos do Estado do Rio Grande do Sul, até hoje a base principal do modelo agrícola é a agricultura familiar com produção diversificada. Apesar deste histórico, de acordo com Mello e Schmidt (2014) a região passa por uma crise, que é, ao mesmo tempo, econômica, social e ambiental. Porém, pesquisas com relação à estas ocorrências vêm sendo realizadas há quase duas décadas. Testa et al (1996) à época já investigavam e identificaram que o êxodo rural e regional, ocorre de forma mais acentuada na parcela mais jovem da população, sendo as mulheres as que deixam "o campo" primeiro.

A afirmação dos autores é ratificada pelos dados apresentados no Caderno de Informações Socioeconômicas do Município de Concórdia, SC (2013) publicado no último mês de abril pela Associação Empresarial do Município que contempla dados do Censo Demográfico do IBGE respectivos ao ano de 2010 , onde o percentual de habitantes na zona rural tem reduzido significativamente ao longo das últimas décadas.

Neste sentido entende-se como primordial a preocupação com a criação de novos modelos de produção agrícola, visando incentivar a permanência das atuais e novas gerações no campo.

Com o objetivo de fortalecer suas atividades, os próprios agricultores do Oeste de Santa Catarina fundaram ao longo das últimas décadas pequenas cooperativas vislumbrando possibilidades de maximizar seus lucros e criar alternativas para viabilizar sua permanência no campo, fator este que demandou a criação da Central de Cooperativas da Agricultura Familiar (CECAF), que surgiu no intuito de dar suporte às cooperativas juntamente com a Empresa de Pesquisa Agropecuária e Extensão Rural de Santa Catarina (EPAGRI).

Estas cooperativas são criadas pela vontade comum de seus cooperados que na maioria das vezes não possuem experiência de gestão e competitividade, demandando desta forma a orientação técnica especializada para manterem-se ativas e gradativamente ganharem espaço e firmarem-se no mercado pela produção de alimentos típicos regionais de qualidade. Pensando nisso, chegou-se a sugestão de realização de um trabalho técnico que possa colaborar com a otimização dos custos de produção e com a criação de estratégias competitivas que evidenciem as vantagens do consumo dos produtos gerados pela agricultura familiar local em detrimento daqueles 
comercializados pelas grandes redes, fortalecendo a imagem destes produtos e colaborando para que as riquezas produzidas na região contribuam para o desenvolvimento regional.

Entendendo a dimensão da proposta de estudo, optou-se, num primeiro momento, em delimitar apenas uma das problemáticas a serem abordadas como proposta inicial e com base nisso definiu-se como objetivo geral desta proposta: "identificar estratégias a serem adotadas pelas cooperativas agroalimentares associadas à CECAF visando fortalecer sua participação no mercado".

Para dar suporte ao alcance do objetivo deste estudo, Como objetivos específicos, foram definidos: (1) Identificar qual o nível de conhecimento e aceitação por parte da população regional acerca da cooperativa e dos produtos por ela comercializados; (2) Identificar qual a capacidade produtiva, de distribuição e de absorção dos produtos no mercado regional;

Este estudo justifica-se em razão da grande quantidade de famílias vinculadas à agricultura familiar, o qual pode colaborar para torná-las mais competitivas, melhorando a qualidade de vida na zona rural, tornando a economia regional mais concreta.

Diante do exposto, este estudo apresenta-se estruturado da seguinte maneira após esta introdução: a segunda seção apresenta os constructos empíricos que tangem sobre conceitos da utilização de redes como estratégia competitiva, cooperativas e a integração da agricultura familiar neste contexto; a terceira seção apresenta a metodologia do estudo; a quarta seção traz os resultados coletados por meio de pesquisa de campo; e a quinta seção trás as conclusões da pesquisa, as limitações e as sugestões para novos estudos.

\section{REVISÃO BIBLIOGRÁFICA}

Este estudo apresenta no decorrer de sua estrutura alguns constructos teóricos que vêm sendo discutidos com relação às estratégias de competitividade existentes na utilização de redes no processo organizacional. Esta seção traz um breve estudo sobre a correlação existente entre as redes e a estratégia competitiva, e na sequencia integra a utilização do cooperativismo regional e a utilização da agricultura familiar como modelo agrícola de produção. 


\subsection{REDES E ESTRATÉGIA COMPETITIVA}

Devido à globalização e as novas tecnologias de informação e da comunicação, as redes organizacionais encontram-se em ascensão repercutindo diretamente na capacidade competitiva das empresas. Questiona-se, neste sentido, o que realmente são redes? Menard (2004) afirma que uma rede é um conjunto de organizações ou de indivíduos engajados, reciprocamente, em transações recorrentes, reguladas segundo uma lógica de coordenação que extrapola o caráter estrito seja do mercado, seja da hierarquia.

O termo rede é utilizado, para designar uma forma particular de associação, de natureza horizontal, que reúne, voluntariamente, atores diversos, que interagem entre si, de maneira sistemática, compartilhando, em menor ou maior grau, certos valores comuns, e implementando, conjuntamente, estratégias de interesse coletivo, visando algum ganho socioeconômico (para empresas, setores e comunidades). (VALE; AMANCIO; LIMA, 2006)

Diversos modelos teóricos abordam temas relacionados a redes. Dentre elas, citam-se a teoria dos jogos (VON NEUMANN E MORGENSTERN, 1944), a teoria dos custos das transações (williamson, 1975; 2005), a teoria das redes SOciais (GRANOVETTER, 1985; 2005), a vertente do capital social (BURT, 2000), as teorias institucionalistas evolucionárias (LUNDVAL, 1988; MALERBA, 2005), a do marketing relacional (GUMMESSON, 1996), e a do capital relacional (VALE, 2006).

Segundo Geindre (2001) os cinco pontos fundamentais que caracterizam uma rede: tempo de existência; confiança; dependência compartilhada e interdependência; especificidade dos propósitos da relação; natureza dos ganhos obtidos. A partir disso a medida que as organizações interagem entre si, amplia-se também a participação em novas redes ou em redes mais abrangentes.

Neste sentido fica evidente a necessidade de interação entre os membros que fazem parte da rede, bem como a capacidade de gestão coletiva. Torna-se fundamental entender a lógica de constituição e funcionamento das redes organizacionais e como as empresas interagem em um modelo cooperativo, característico dessas novas estruturas de empresa. Vale, Amâncio e Lima (2006) afirmam ainda que além da integração das empresas em rede repercutir diretamente no desempenho organizacional das empresas, a qualidade das redes existentes e suas relações em um determinado local contribui para constituir fatores competitivos no processo de desenvolvimento local.

Porém, a região oeste do estado de Santa Catarina é caracterizada, em sua grande maioria, por pequenos produtores agrícolas, o que acaba por 
dificultar a competitividades destes diante do mercado. A seção seguinte trata com maior profundidade como se caracteriza o modelo agrícola regional de Santa Catarina.

\subsection{O MODELO AGRícola CATARINENSE E O SURGIMENTO DE NOVAS ALTERNATIVAS DE PRODUÇão NA AGRICULTURA FAMILIAR}

A agricultura familiar é a base da formação social e econômica do Estado de Santa Catarina que é caracterizado por possuir, no campo, pequenas propriedades, onde a família controla os meios de produção e executa o trabalho e onde a ordem social do colono funda-se na ligação entre a propriedade, família e trabalho. (KONRAD e SILVA, 2012).

Esta informação embasa-se no último Censo Agropecuário realizado pelo Instituto Brasileiro de Geografia e Estatística (IBGE) em 2006 onde pode-se concluir que do total de estabelecimentos rurais do Estado de Santa Catarina, $87 \%$ classificam-se como estabelecimentos com predomínio total da agricultura familiar.

Segundo Mior et al (2013) este percentual faz de Santa Catarina uma das unidades da federação com os maiores percentuais de agricultores familiares do Brasil. O autor destaca ainda que essa maioria absoluta detém apenas $44 \%$ da área total e é responsável por $64 \%$ do valor bruto total da produção dos estabelecimentos agropecuários do Estado. Em relação à estrutura fundiária, o autor afirma ainda que predominam estabelecimentos com pequena área, onde $65 \%$ possuem menos que 20 hectares e $36 \%$ têm menos de 10 hectares de área total.

Mior et al (2013) destacam ainda que a agricultura familiar catarinense possui como característica a diversificação de sua base produtiva, combinando produtos vegetais com a criação de animais, onde são presentes formas altamente sofisticadas de produção no sistema de integração agroindustrial bem como práticas tradicionais de autoconsumo e troca entre vizinhos, articulação com mercados locais, redes mercantis informais e integração em circuitos mais formais de comercialização. Apesar deste cenário, há um expressivo número de pequenas e médias propriedades rurais, produtoras de alimentos básicos e de matérias primas, que apresentam baixos níveis de renda e dificuldades em se manter produzindo. Assim, lado a lado convivem ambas as formas, empresarial e camponesa de se fazer agricultura.

Para Altmann et al (2008), o baixo nível de renda e a insatisfatória qualidade de vida para boa parte das famílias rurais vêm provocando, nos últimos anos, um 
êxodo rural com tendência a acelerar-se num processo de masculinização e envelhecimento dessa população. Os autores destacam ainda que em função disso e de diversas transformações significativas no modo de viver, de produzir e de trabalhar dos agricultores familiares, emergem novos atores sociais e se ampliam os espaços e as relações entre o mundo rural e urbano.

Este movimento caracteriza a luta dos agricultores por buscar maior autonomia e capturar valor nas principais cadeias de alimentos, criando seus próprios empreendimentos e se inserindo nos diversos mercados a partir da organização em associações e cooperativas o que implica também em recuperar e revalorizar processos artesanais de um "saber-fazer" que resgatam um patrimônio histórico e cultural da sociedade catarinense. (MIOR, et al, 2013) Neste sentido, Wilkinson (2008) destaca que a demanda de produtos do sistema agroalimentar não é caracterizada apenas pelo critério de quantidade/ preço e dá importante lugar à economia da qualidade.

Ferrari (2011) complementa afirmando que em Santa Catarina é possível verificar a emergência de uma ampla variedade de novas cadeias alimentares que são caracterizadas pelas noções de qualidade, tradição, re-localização e imersão em redes sociais.

Diante do exposto a literatura consultada evidencia para a abertura de novos nichos de mercado a serem explorados pelas novas formas de organização e processos (grupos, cooperativas, filiais, marcas, selos, redes) que apresentam grande potencial para desencadear amplos processos de desenvolvimento rural nos diferentes contextos e territórios, sendo que constructos relacionados a estes assuntos não serão abordados, visto não corroborarem com o objeto deste estudo.

\section{PROCEDimentos Metodológicos}

Para Beuren (2004), uma pesquisa na área das ciências sociais aplicadas pode ser caracterizada quanto aos seus objetivos, procedimentos, estratégia de coleta de dados e pelas técnicas de análise utilizadas. Neste sentido o presente estudo caracteriza-se, quanto ao seu objetivo, como explicativo.

Para Santos(1999) as pesquisas explicativas consistem em descobrir os porquês de fatos e fenômenos da realidade, ou seja, identificar os fatores que contribuem ou são determinantes para a ocorrência de determinado fato ou fenômeno. Vergara (2013, p.42) complementa dizendo que "a investigação explicativa tem como principal objetivo tornar algo inteligivel, justificar lhe os motivos". 
Quanto à abordagem do problema, trata-se de uma pesquisa mista qualitativa e quantitativa. De acordo com Denzin et al (2006) a pesquisa qualitativa envolve o estudo do uso e coleta de uma variedade de materiais empíricos, que descrevem momentos e significados rotineiros e problemáticos na vida dos indivíduos. A pesquisa qualitativa pode ainda caracterizar-se como sendo qualquer tipo de pesquisa que produza resultados não alcançados por meio de procedimentos estatísticos ou de outros meios de quantificação. (strauss; CORBIN; 2008)

Como destacado anteriormente, esta pesquisa se caracteriza como mista, dessa forma, utiliza-se também de elementos quantitativos para atingir seus objetivos. Neste sentido, Cooper e Schindler (2011) destacam que a pesquisa quantitativa tenta mensurar algo com precisão. Os autores destacam ainda que este tipo de pesquisa na administração, normalmente mede comportamento, conhecimento, opiniões ou atitudes do consumidor, sendo que visam responder questões relacionadas a quanto, com que frequência, quantos, quando e quem, sendo que, embora o levantamento não seja a única metodologia do pesquisador quantitativo, ele é considerado o mais importante.

Em relação aos seus procedimentos, trata-se de uma pesquisa de levantamento/Survey. O procedimento Survey de coleta de dados, de acordo com Mello (2013), é um método de coleta de informações diretamente de pessoas a respeito de suas ideias, sentimentos, saúde, planos, crenças e de fundo social, educacional e financeiro na qual a coleta de informações é feita por meio de questionários, aplicados no público alvo escolhido para realização da pesquisa.

Desta forma, é possivel delimitar que a população deste estudo será composta pelas cooperativas agroalimentares associadas à CECAF e o período utilizado para a coleta e análise de dados foi de Agosto à Dezembro de 2014.

A coleta dos dados será dividida em três etapas. Para realização da primeira etapa do estudo, será elaborado um breve questionário estruturado destinado à população da região onde os produtos são comercializados pela CECAF, com o intuito de responder ao objetivo específico do estudo quanto ao nível de conhecimento e aceitação da população em relação aos produtos da agricultura familiar. Em um segundo momento serão aplicados questionários aos cooperados e associados buscando responder ao objetivo de identificar qual a capacidade produtiva, de distribuição e de absorção dos produtos no mercado regional. Por fim, a terceira etapa de coleta de dados, será realizada uma entrevista semiestruturada com o dirigente da CECAF, visando integrar os dados coletados, possibilitando assim a triangulação das informações, bem como analisar quais estratégias podem corroborar para atingir o objetivo 
central deste estudo, qual seja, identificar estratégias a serem adotadas pelas cooperativas com vistas a fortalecer sua participação no mercado.

O questionário, segundo Günther (2003) é um instrumento que pode ser definido como "um conjunto de perguntas sobre um determinado tópico que não testa a habilidade do respondente, mas mede sua opinião, seus interesses”, enquanto Manzini (1990/1991), afirma que a entrevista semiestruturada está focalizada em um assunto sobre o qual confeccionamos um roteiro com perguntas principais, complementadas por outras questões inerentes às circunstâncias momentâneas à entrevista. Para o autor, esse tipo de entrevista pode fazer emergir informações de forma mais livre e as respostas não estão condicionadas a uma padronização de alternativas.

Martins (2002) aponta que os dados coletados podem ser caracterizados como primários ou secundários, sendo que o primeiro corresponde aos dados provenientes da aplicação de instrumentos diretos aos sujeitos da pesquisa, como questionários e entrevistas. O segundo contempla os dados que são obtidos por meio de cadastros e publicações. Nesta pesquisa, dentre os dados primários coletados destaca-se a utilização de questionários e a entrevistas, enquanto os dados secundários limitar-se-ão a documentos publicados e disponibilizados pelas cooperativas e pela associação.

Com relação à análise, Marconi e Lakatos, (2005) afirmam ser o momento em que o pesquisador obtém as respostas ao problema da pesquisa, estabelecendo as relações necessárias entre os dados e as hipóteses formuladas, comprovando-as ou refutando-as de acordo com a análise dos dados.

Por fim serão analisados os dados obtidos por meio da pesquisa, comparando-os e identificando se existem maneiras de propiciar aos cooperados ações para aumentarem sua participação no mercado onde atuam, e possivelmente expandir para outros mercados.

\section{ANÁLISE dos RESULTAdos}

Nesta seção serão apresentados os resultados obtidos e as análises realizadas com a triangulação dos dados coletados, e para que isso seja possível, primeiramente é necessária que seja caracterizada a organização objeto deste estudo. 


\subsection{CARACTERIZAÇÃo DA ORGANIZAÇÃo}

Fundada em 19 de maio de 2006, a Central de Cooperativas da Agricultura Familiar - CECAF é uma organização formada exclusivamente por cooperativas singulares associadas. Essas cooperativas são formadas por pequenos produtores familiares localizados no Oeste de Santa Catarina. No Quadro 1 estão apresentadas as cooperativas associadas à CECAF e as cidades onde cada uma delas está sediada.

\section{QUADRO 1 - COOPERATIVAS AFILIADAS À CECAF}

\begin{tabular}{|l|l|l|l|}
\hline & COOPERATIVA & NOME & CIDADE \\
\hline 1 & COAFAMO & $\begin{array}{l}\text { Cooperativa dos Agricultores } \\
\text { Familiares e Industrial de Mondaí }\end{array}$ & Mondaí \\
\hline 2 & COAFASC & $\begin{array}{l}\text { Cooperativa dos Agricultores } \\
\text { Familiares de Bom Retiro }\end{array}$ & Bom Retiro \\
\hline 3 & COONAFOR & $\begin{array}{l}\text { Cooperativa de Produção } \\
\text { Agroindustrial dos Agricultores } \\
\text { Familiares de Forquilhinha }\end{array}$ & Forquilhinhas \\
\hline 4 & COOPASE & $\begin{array}{l}\text { Cooperativa de Produção e Consumo } \\
\text { dos Produtores e das Agroindústrias } \\
\text { Familiares de Seara }\end{array}$ & Seara \\
\hline 5 & COFAC & $\begin{array}{l}\text { Cooperativa de Produção } \\
\text { Agroindustrial de Concórdia }\end{array}$ & Concórdia \\
\hline 6 & COFAPAL & $\begin{array}{l}\text { Cooperativa de produção e Consumo } \\
\text { Agroindustrial Familiar de Lindóia do } \\
\text { Sul }\end{array}$ & Lindóia do Sul \\
\hline 7 & COPAFAPER & $\begin{array}{l}\text { Cooperativa de produção } \\
\text { Agroindustrial Familiar de Peritiba }\end{array}$ & Peritiba \\
\hline 8 & COPAGRAI & $\begin{array}{l}\text { Cooperativa Agroindustrial do Alto } \\
\text { Irani }\end{array}$ & Irani \\
\hline 9 & COPER ABV & $\begin{array}{l}\text { Cooperativa dos Agricultores } \\
\text { Familiares de Alto Bela Vista }\end{array}$ & Alto Bela Vista \\
\hline 10 & COPERARABUTÃ & $\begin{array}{l}\text { Cooperativa dos Agricultores } \\
\text { Familiares de Arabutã }\end{array}$ & Arabutã \\
\hline 11 & COPERAGIR & $\begin{array}{l}\text { Cooperativa Agroindustrial Familiar } \\
\text { de Iraceminha }\end{array}$ & Iraceminha \\
\hline 12 & COPERARVOREDO & $\begin{array}{l}\text { Cooperativa de Produtores Familiares } \\
\text { de Arvoredo }\end{array}$ & Arvoredo \\
\hline
\end{tabular}


REDES ORGANIZACIONAIS: UM ESTUDO DAS ESTRATÉGIAS DE COMPETITIVIDADE EM COOPERATIVAS DA AGRICULTURA FAMILIAR DO OESTE DE SANTA CATARINA

\begin{tabular}{|c|c|c|c|}
\hline 13 & COPERCASTELO & $\begin{array}{l}\text { Cooperativa de Produção e Consumo } \\
\text { Agroindustrial Familiar de Presidente } \\
\text { Castelo Branco }\end{array}$ & $\begin{array}{l}\text { Presidente } \\
\text { Castelo Branco }\end{array}$ \\
\hline 14 & COPERJABORÁ & $\begin{array}{l}\text { Cooperativa de Produção e Consumo } \\
\text { Agroindustrial de Jaborá }\end{array}$ & Jaborá \\
\hline 15 & COPERMIRIM & $\begin{array}{l}\text { Cooperativa de Produção } \\
\text { Agroindustrial e Artesanal Familiar de } \\
\text { Ipumirim }\end{array}$ & Ipumirim \\
\hline 16 & COPERPAIAL & $\begin{array}{l}\text { Cooperativa de Produção e Consumo } \\
\text { Agroindustrial Familiar de Paial }\end{array}$ & Paial \\
\hline 17 & $\begin{array}{l}\text { COPER SABOR DO } \\
\text { SUL }\end{array}$ & Cooperativa Sabor do Sul & Concórdia \\
\hline 18 & COPROPPI & $\begin{array}{l}\text { Cooperativa de Pequenos Produtores } \\
\text { de Piratuba }\end{array}$ & Piratuba \\
\hline 19 & CPAMI & $\begin{array}{l}\text { Cooperativa de produtores } \\
\text { Agroindustriais do Município de Ipira }\end{array}$ & Ipira \\
\hline 20 & COPERPINHAL & $\begin{array}{l}\text { Cooperativa Agroindustrial Familiar } \\
\text { de Pinhal }\end{array}$ & Concórdia \\
\hline 21 & COPERITÁ & $\begin{array}{l}\text { Cooperativa de Produtores Familiares } \\
\text { de Itá }\end{array}$ & Itá \\
\hline
\end{tabular}

FonTE: DAdOS DA PESQUISA

A CECAF tem por objetivo prestar serviços em tecnologia de produção, comercialização dos produtos da agricultura familiar, profissionalização dos associados e a organização em comum e em maior escala dos serviços sociais, econômicos, financeiros e assistenciais de interesse das filiadas, integrando e orientando suas atividades, bem como facilitando a utilização recíproca dos serviços, e é por meio das cooperativas filiadas que a CECAF alcança esses agricultores.

Dentre as principais funcionalidades da CECAF pode-se citar: I - desenvolver atividades que garantam o desenvolvimento da produção agropecuária e agroindustrial de seus associados; II - garantir a distribuição equitativa, tanto de seus custos e encargos quanto de seus excedentes; III - prestar assistência educacional e social para o aprimoramento humano e profissional dos associados e colaboradores; IV - realizar operações comerciais, e financeiras facilitando a comercialização dos produtos produzidos pelas filiadas; $\mathrm{V}$ - promover registro de marcas e patentes e código de barras para produtos e serviços da Central e Filiada; VI - contratar técnicos, agenciar propaganda, publicidade e afins; VII - operar com transportes, etc.

Apresentada a organização e demonstrado como é o funcionamento dessa rede de cooperativas, prossegue-se no estudo apresentando os resultados 
obtidos por meio dos questionários aplicados e entrevista realizada.

\subsection{ANÁLISE dos DADOS COLETAdos}

A coleta de dados realizada nas cooperativas apresentou retorno de 14 questionários, sendo que 7 das cooperativas não responderam ou não foram localizadas no período disposto para o estudo. Dentre os respondentes, a maior parte das cooperativas está associada à CECAF há no máximo 3 anos, conforme pode ser visualizado na Figura 1.

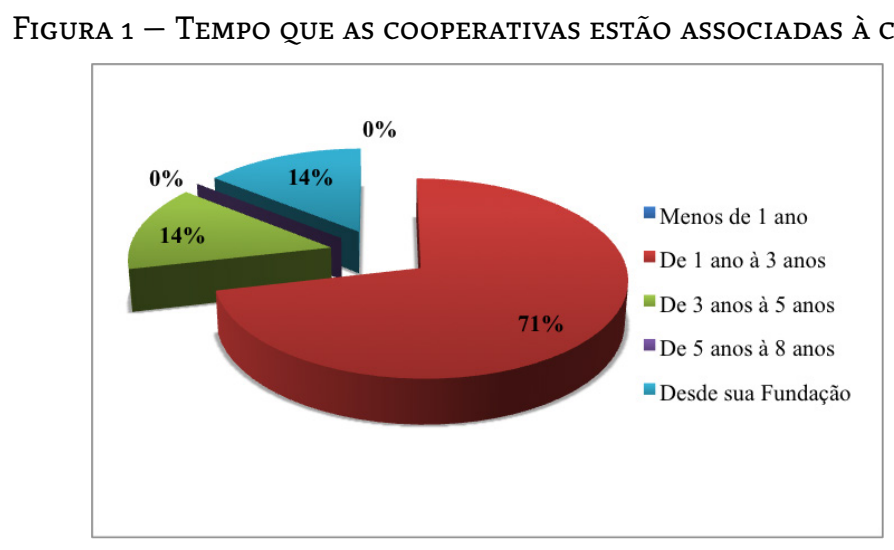

Fonte: DAdos DA PESQUisa

Nota-se a partir da Figura 1 que $71 \%$ das cooperativas analisadas estão filiadas à CECAF há menos de 3 anos, o que demonstra que a mesma vem aos poucos aprimorando sua estrutura e fortalecendo sua atuação no oeste de Santa Catarina. Dentre os respondentes, encontram-se ainda $14 \%$ que estão filiados de 3 a 5 anos e outros 14\% que atuam com a CECAF desde sua fundação. Por intermédio da entrevista, verificou-se que em 2014 outras quatro cooperativas iniciaram o processo de filiação, porém ainda não estão regularmente cadastradas, desse modo, também não fizeram parte deste estudo. Como é prática em associações e cooperativas, a diretoria da CECAF é formada por membros das cooperativas filiadas, sendo que neste estudo optou-se em aplicar os questionários nos mais diversos níveis da organização, que pode ser visualizado na Figura 2. 


\section{FigURA 2 - COMPOSIÇÃo DOS ENTREVISTADOS NA DIRETORIA DA CECAF}

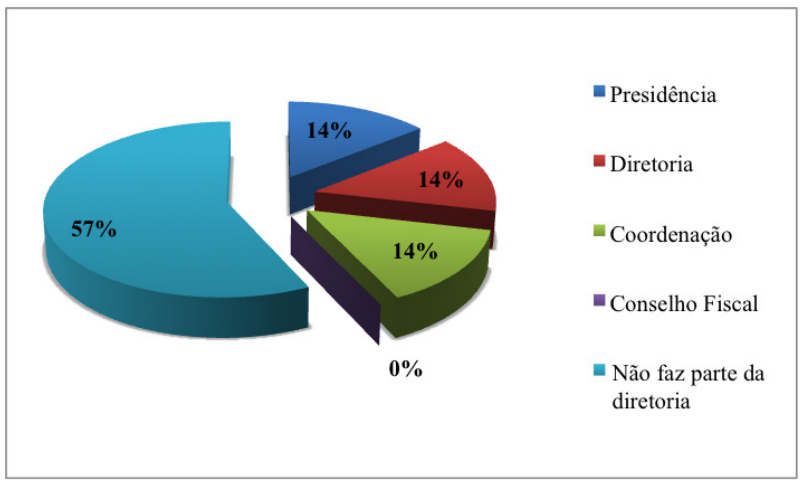

FonTE: DAdos DA PEsQUisa

Nota-se que mais da metade dos entrevistados não participam da CECAF em cargos de gestão, sendo apenas colaboradores filiados à associação. Já a quantidade de membros da presidência, diretoria e de cargos de coordenação ficaram com $14 \%$ cada, dentre as cooperativas onde foram aplicados os questionários.

Foi questionado às cooperativas o percentual que representa as vendas dos produtos por meio da CECAF, sendo que o resultado apresentou que aproximadamente $60 \%$ dos entrevistados destinam para comercialização pela Central, apenas $25 \%$ do total que produzem, sendo que os demais $40 \%$ destinam entre $50 \%$ e $75 \%$ de sua produção para comercialização pela CECAF.

Esses percentuais se comportam dessa maneira em função de todas as cooperativas questionadas já estarem no mercado antes de filiarem-se à CECAF, realizando vendas sem o auxílio de uma cooperativa central. Dentre os produtos com vendas mais significativas na CECAF, destaca-se os pescados, frutas (in natura, geleias e sucos), verduras, grãos (arroz, feijão,...), farinha de milho e panificados. Verificou-se também que alguns cooperados atuam com venda de produtos diferenciados, porém em baixa quantidade, sendo que os que se destacam são o queijo temperado e as combinações de sabores na fabricação das geleias.

Questionou-se então o comportamento dos preços de venda praticados pela CECAF comparados com os preços do comércio em geral, onde a grande maioria dos questionamentos destacam que o preço praticado é equivalente ao comércio da região, entretanto, de acordo com a entrevista realizada com o presidente, $5 \%$ do preço de venda é destinado à manutenção dos custos e 
gastos que a CECAF possui.

Outro questionamento realizado foi se a filiação à CECAF colaborou para o aumento na comercialização dos produtos, do qual obteve-se $70 \%$ de retorno afirmando que contribui para o aumento das vendas, mas que ainda assim o contentamento dos cooperados não está em um nível aceitável, sendo que a solução mais citada é que deveria ser investido mais em divulgação e marketing dos produtos.

Verificou-se que diversas entre as cooperativas analisadas contam com o apoio de órgãos governamentais em sua produção, com destaque à inclusão dos produtos da agricultura familiar na merenda escolar dos municípios, apoio da secretaria municipal de agricultura e da Epagri - Empresa de Pesquisa Agropecuária e Extensão Rural de Santa Catarina por meio de cursos e visitas técnicas, e ainda contam com o auxílio da Feira Municipal da Agricultura Familiar, que acontece anualmente e é uma oportunidade dos cooperados divulgarem seus produtos e aumentar suas vendas. Por meio da entrevista, confirmou-se essa informação e estacou-se que além desses benefícios existe ainda o ato cooperado, incentivos como o SC Rural e o valor pago por financiamentos governamentais é menor quando realizado por intermédio da CECAF.

Outro fator pesquisado foi a capacidade de produção que os cooperados possuem. Este questionamento possibilitou evidenciar que a maior parte das cooperativas entrevistadas possui capacidade de aumento de sua produção de $50 \%$ a $100 \%$ se comparado com a produção atual. Esse resultado aponta que a CECAF demanda investir mais em publicidade visando aumentar as vendas com objetivo de reduzir a ociosidade dos filiados.

$\mathrm{Na}$ última pergunta do questionário optou-se em apresentá-la de forma completamente aberta, e perguntava aos participantes sobre o quê, na opinião das cooperativas, poderia ser melhorado na CECAF para alavancar a quantidade de venda de produtos. As respostas obtidas ressaltaram necessidades diversificadas, que foram classificadas em quatro itens, os quais encontram-se relacionados no Quadro 2.

\section{QUADRO 2 - SugESTÕES DE MELHORIAS POR PARTE DOS COOPERADOS}

\begin{tabular}{|l|l|}
\hline $\begin{array}{l}\text { Publicidade e } \\
\text { Propaganda }\end{array}$ & $\begin{array}{l}\text { Há necessidade de ampliação de investimentos relativos } \\
\text { à publicidade e propaganda, bem como é fundamental } \\
\text { a criação de um site institucional e maior divulgação do } \\
\text { programa "Café Colonial", o que colaborará para ampliar } \\
\text { a venda dos produtos. }\end{array}$ \\
\hline
\end{tabular}




\begin{tabular}{|l|l|}
\hline $\begin{array}{l}\text { Criação de novas } \\
\text { estratégias de venda }\end{array}$ & $\begin{array}{l}\text { Dentre as sugestões contempladas neste item, destaca-se } \\
\text { a implantação das feiras livres e dos “tickets feira" em } \\
\text { empresas da região; a ampliação do programa "Café } \\
\text { Colonial" buscando inseri-lo anualmente nos calendários } \\
\text { de eventos dos municipios de abrangência da CECAF; dar } \\
\text { continuidade aos projetos para atendimento da merenda } \\
\text { escolar; melhorar de forma geral a qualidade dos } \\
\text { produtos comercializados pela cECAF. }\end{array}$ \\
\hline $\begin{array}{l}\text { Melhoria dos preços de } \\
\text { comercialização dos } \\
\text { produtos }\end{array}$ & $\begin{array}{l}\text { Foi ponderada a necessidade de revisão dos preços dos } \\
\text { produtos comercializados, em especial aos que fazem } \\
\text { parte dos projetos da Conab, assim como oportunizar } \\
\text { preços de maior acessibilidade ao consumidor. }\end{array}$ \\
\hline $\begin{array}{l}\text { Incentivos } \\
\text { Governamentais }\end{array}$ & $\begin{array}{l}\text { Há preocupação das cooperativas a ocorrência do êxodo } \\
\text { rural e a necessidade de incentivo por parte do poder } \\
\text { público para a permanência dos produtores familiares no } \\
\text { campo. }\end{array}$ \\
\hline
\end{tabular}

FonTE: DAdos dA PESQUisa

Após a análise realizada sobre os dados coletados dos cooperados, analisa-se os dados coletados com a população consumidora e da entrevista com o presidente da CECAF. Por meio da entrevista, foi possível verificar que os produtos da CECAF são comercializados, na sua grande maioria, pela Casa do Produtor, mercados, padarias e fruteiras das cidades abrangidas pela Cefaf.

A pesquisa realizada com 109 munícipes retornou a frequência como os produtos da CECAF são consumidos em suas residências. O resultado está apresentado na Figura 3.

\section{FiguRA 3 - FREQUÊNCIA DE CONSUMO DA POPULAÇÃO PESQUISADA}

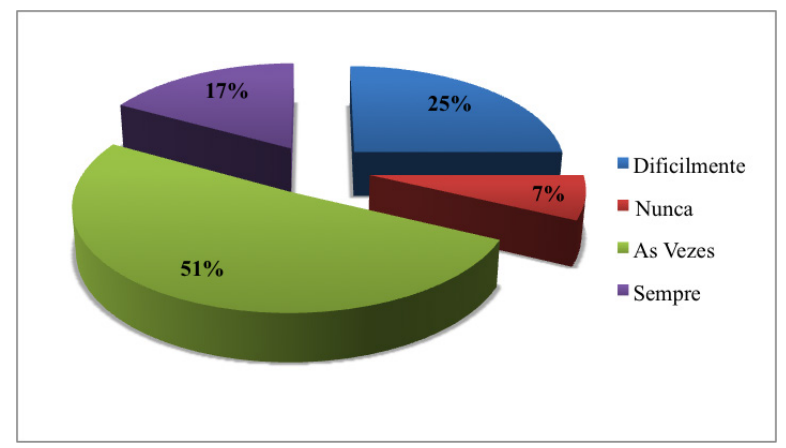

FonTE: DAdos DA PESQUisA 
Pode-se verificar na Figura 3 que $17 \%$ da população pesquisada tem por hábito sempre adquirir produtos da agricultura familiar, acompanhado por $51 \%$ que afirma às vezes comprar esses produtos. Os $32 \%$ restante afirmam dificilmente ou nunca comprar esses produtos, dando preferência na aquisição de produtos industrializados em escala ou de grandes empresas.

A população foi questionada também com relação ao retorno que os produtos dos cooperados da CECAF trazem à economia local. Este questionamento teve por resultado que contribui com a economia, porém ainda representa parcela bastante reduzida PIB municipal. A Figura 4 apresenta a composição dos resultados decorrentes desta questão.

\section{FiguRA 4 - OPINIÃO DA POPULAÇÃo COM RELAÇÃO AO RETORNO QUE OS PRODUTOS DA CECAF TRAZEM AO MUNicípio}

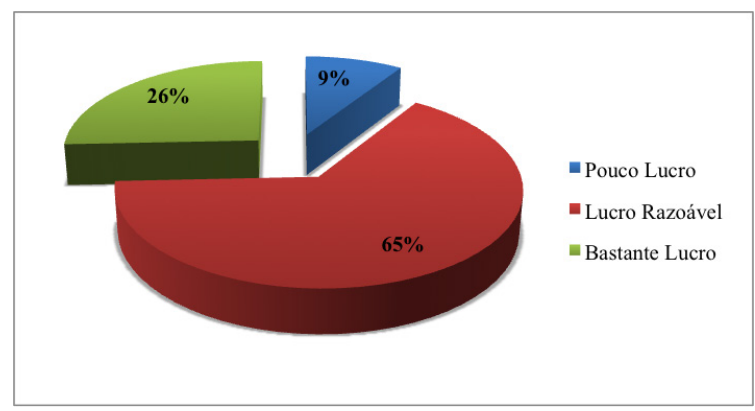

Fonte: DAdos DA PESQUisa

O questionamento final da pesquisa buscou evidenciar a opinião do entrevistado com relação a esse modelo de rede cooperativista. Os resultados apontam que esse modelo de cooperativa é de extrema importância para a região, e que este modelo deveria ser mais incentivado pelos órgãos públicos, e também pelos consumidores. Em complemento alguns comentaram: "além de fornecer produtos diferenciados, é capaz de gerar empregos, tornando-se uma boa forma de renda para a cidade, o que possibilita que a cidade evolua". "Os produtores locais deveriam ser mais valorizados, sem contar que os alimentos são saudáveis". "O mais interessante neste sistema é a oportunidade aos pequenos produtores para comercializar seus produtos". "Deve haver incentivo e orientação à população acerca dos prós em relação ao consumo dos produtos da região". "Ainda faltam muitos investimentos neste ramo e deveríamos incentivar essas atividades". "Além de o processo ser econômico e ter geração de lucro futuros, acredito que todo órgão competente deveria 
dar apoio sim". "Precisamos desses tipos de serviços para nossa sustentabilidade". "O governo também incentiva com ajuda financeira, maquinário e incentivando à venda, mas deveria ser ainda mais valorizado, pois gera emprego e renda para muitas famílias". "A região é uma das únicas do Brasil que não precisa de reforma agraria. Pois é própria da região a Policultura. $\mathrm{O}$ incentivo do governo deve focar em manter esse sistema".

Por meio da entrevista com o presidente, foi possível ainda identificar as principais dificuldades enfrentadas pelas cooperativas e pela própria CECAF na realização dos trabalhos. O resultado apresenta que o principal ônus sobre a operação é a carga tributária e a burocracia exigida pelo fisco.

Esta seção trouxe a caracterização da instituição e dos dados coletados pela pesquisa de campo realizada nas cooperativas e na população onde está localizada a CECAF. Diante das informações dispostas, a seção seguinte apresenta as conclusões deste estudo.

\section{CONCLUSÕES}

Este estudo teve como objetivo identificar estratégias que podem ser adotadas pelas cooperativas agroalimentares associadas à CECAF visando fortalecer sua participação no mercado. Teve como suporte objetivos específicos, os quais visaram identificar qual o nível de conhecimento e aceitação por parte da população regional acerca da cooperativa e dos produtos por ela comercializados e identificar qual a capacidade produtiva, de distribuição e de absorção dos produtos no mercado regional.

Conclui-se após analisados os dados que a CECAF, visando alavancar as vendas, poderia investir mais em marketing para os produtos por ela comercializados. Outros investimentos em qualidade de produtos e aperfeiçoamento de técnicas produtivas poderiam colaborar para o aumento das vendas na CECAF.

Outro fator que pôde ser identificado foi que os produtos são comercializados apenas nos municípios onde as cooperativas estão instaladas, o que por consequência acaba restringindo as vendas e gerando ociosidade na produção das cooperativas filiadas. Outro fator identificado no estudo é que poderiam ser revisados os preços dos produtos tornando-os mais competitivos que o mercado em geral, até mesmo para que as cooperativas consigam aprimorar as parcerias com o governo municipal, passando a disponibilizar maior quantidade de produtos para a merenda escolar.

Por fim, um fator que poderia ser utilizado como fator de competitividade 
e que poderia apresentar bons retornos aos cooperados são investimentos em produtos diferenciados, como por exemplo, produtos orgânicos. Esses produtos possuem um valor agregado maior que os produtos normais e possibilitam ao produtor um incremento em sua lucratividade.

Este estudo apresentou algumas limitações, dentre as quais destaca-se o retorno dos questionários aplicados nas cooperativas, onde $1 / 3$ não respondeu ou não puderam ser encontradas e, a entrevista que acabou por não ter consistência em suas respostas. Sugere para próximas pesquisas que se façam comparativos entre cooperativas visando identificar fatores que possam colaborar para o aumento das vendas e da competitividade dos produtos no mercado.

\section{REFERÊNCIAS}

ALTMANN, Rubens; MIOR, Luiz Carlos; ZOLDAN, Paulo (2008). "Perspectivas para o sistema agroalimentar e o espaço rural de Santa Catarina em 2015”. Florianópolis, Epagri. Disponível em: <http://docweb.epagri. sc.gov.br/website_cepa/publicacoes/sistema_agroalimentar.pdf $>$ Acesso em: 18 dez 2014.

BEUREN, Ilse Maria (2004). Como elaborar trabalhos monográficos em contabilidade: teoria e prática. São Paulo: Atlas.

COOPER, Donald; SCHINDLER, Pamela (2011). Métodos de Pesquisa em Administração. 10a Edição, Porto Alegre: Bookman.

DENZIN, Norman; LINCOLN, Yvonna (2006). O planejamento da pesquisa qualitativa: teorias e abordagens. Porto Alegre: Artmed.

FERRARI, Dilvan Luiz. "Agricultura familiar: trabalho e desenvolvimento no Oeste de Santa Catarina”. Dissertação de Mestrado apresentada ao Instituto de Economia da UNICAMP. Campinas, 2003. Disponivel em: http://www. bibliotecadigital.unicamp.br/document $/$ code $=$ vtlso00308780 Acesso em: 01 nov 2014.

GÜNTHER, Hartmut. "Como elaborar um questionário" (Série: Planejamento de Pesquisa nas Ciências Sociais, N.1) Brasília, DF: UnB, Laboratório de Psicologia Ambiental. Disponível em: www.psicologia-ambiental.net/pdf/ 01Questionario.pdf Acesso em: 15 out 2014.

KONRAD, Joice; SILVA, Clécio Azevedo da (2012). "Agricultura Familiar No Oeste Catarinense: da Colônia à Integração”. XXI Encontro Nacional de Geografia Agrária. Universidade Federal de Uberlândia. ISSN 1983-487X. Uberlândia. Disponivel em: http://www.lagea.ig.ufu.br/xx1enga/anais_ 
enga_2012/eixos/1153_1.pdf Acesso em: 25 out 2014.

LOURENZANI, Wagner Luiz (2006). "Capacitação gerencial de agricultores familiares: uma proposta metodológica de extensão rural”. In: Organizações Rurais e Agroindustriais/Revista de Administração da UFLA, Lavras, volume 8 - n.3 - set./dez.

MANZINI, Eduardo José (1990). “A entrevista na pesquisa social”. Didática: São Paulo, v. 26/27, p. 149-158. Disponivel em: <http://www.periodicos.uem.br/ ojs/index.php/Percurso/article/viewFile/18577/10219> Acesso em: $10 \mathrm{dez}$ 2014.

MARCONI, Maria de Andrade.; LAKATOS, Eva Maria (2005). Fundamentos de metodologia científica. 6. ed. São Paulo: Atlas.

MARTINS, Gilberto de Andrade; THEÓPHILO, Carlos Renato (2002). Metodologia da investigação científica para ciências sociais aplicadas. São Paulo: Editora Atlas.

MELLO, Márcio; SCHMIDT, Wilson (2014). "A agricultura familiar e a cadeia produtiva do leite no Oeste catarinense: possibilidades para a construção de modelos heterogêneos". In PAULILO, M.I.S; SCHIDT, W. A agricultura e o espaço rural em Santa Catarina. Florianópolis: Editora da UFSC.

MELLO, Carlos. (Org.) (2013)."Métodos quantitativos: pesquisa, levantamento ou Survey".Aula o9 da disciplina de metodologia de pesquisa na UNIFEI. Disponível em: http://www.carlosmello. unifei.edu.br/Disciplinas/ Mestrado/PCM-10/Slides-Mestrado/Metodologia_Pesquisa_2012-Slide_ Aula_9_Mestrado.pdfAcesso em: 20 out. 2013.

MENARD, Claude (2004). Économie des organisations. Paris: La Decouverte.

MIOR, Luiz Carlos; FERRARI, Dilvan Luiz; MARCONDES, Tabajara; MONDARDO, Mondardo (2013). "Redes e Agroindústrias: as Inovações Organizacionais Dos Agricultores Familiares $e$ os Novos Mercados em Santa Catarina". $51^{\circ}$ Congresso da Sociedade Brasileira de Economia, Administração e Sociologia Rural (SOBER). Universidade Federal do Pará, Campus Guamá. Belém-PA. Disponível em: http://www.sober.org.br/ palestra/12/ 05O287.pdf Acesso em: 25 out 2014.

MUNICÍPIO DE CONCÓRDIA (2014). Caderno de Informações Socioeconômicas do Município de Concórdia. Concórdia. Disponível em: http://www.acicconcordia.org.br /arquivos_download/projeto_analise_ cidades_anual_07_08_2014.pdf Acesso em: 01 nov 2014.

OLIVEIRA, José Antônio Puppin (2013). Empresas na sociedade: sustentabilidade e responsabilidade social. Rio de Janeiro, ed. Elsevier.

SANTOS, Antônio Raimundo (1999). Metodologia Científica: a construção do conhecimento. Rio de Janeiro: DP\&A. 
STRAUSS, Anselm; CORBIN, Juliet (2008). Pesquisa qualitativa: técnicas $e$ procedimentos para o desenvolvimento de teoria fundamentada. 2. Ed. Porto Alegre: Artmed.

VALE; Glaucia Maria Vasconcelos; AMANCIO, Robson; LIMA, Juvêncio Braga (2006). "Criação e gestão de redes: uma estratégia competitiva para empresas e regiões”. R. Adm. São Paulo, v.41, n.2, p.136-146, abr./maio/jun. Disponível em: <www.rausp.usp.br/download.asp?file $=\mathrm{V}$ 4102136.pdf> Acesso em: 16 Nov 2014.

VERGARA, Sylvia Constant (2013). Projetos e Relatórios de Pesquisa em Administração. São Paulo: Ed. Atlas S.A.

WILKINSON, John (2008). Mercados, redes e valores: o novo mundo da agricultura familiar. Porto Alegre: UFRGS. 
REDES ORGANIZACIONAIS: UM ESTUDO DAS ESTRATÉGIAS DE COMPETITIVIDADE EM COOPERATIVAS DA AGRICULTURA FAMILIAR DO OESTE DE SANTA CATARINA

REDES.COM N ${ }^{\circ} 12 \mid 263$ 